\title{
Room-temperature heteroepitaxy of single- phase Al1-xInxN films with full composition range on isostructural wurtzite templates
}

Ching-Lien Hsiao, Justinas Palisaitis, Muhammad Junaid, Per O A Persson, Jens Jensen, Qingxiang Zhao, Lars Hultman, Li-Chyong Chen, Kuei-Hsien Chen and Jens Birch

\section{Linköping University Post Print}

\begin{abstract}
N.B.: When citing this work, cite the original article.
\end{abstract}
Original Publication:

Ching-Lien Hsiao, Justinas Palisaitis, Muhammad Junaid, Per O A Persson, Jens Jensen, Qingxiang Zhao, Lars Hultman, Li-Chyong Chen, Kuei-Hsien Chen and Jens Birch, Roomtemperature heteroepitaxy of single-phase Al1-xInxN films with full composition range on isostructural wurtzite templates, 2012, Thin Solid Films, (524), , 113-120.

http://dx.doi.org/10.1016/j.tsf.2012.09.072

Copyright: Elsevier

http://www.elsevier.com/

Postprint available at: Linköping University Electronic Press http://urn.kb.se/resolve?urn=urn:nbn:se:liu:diva-86626 


\title{
Room-temperature heteroepitaxy of single-phase $\mathrm{Al}_{1-\mathrm{x}} \mathrm{In}_{\mathrm{x}} \mathrm{N}$ films with full composition range on isostructural wurtzite templates
}

\author{
Ching-Lien Hsiao ${ }^{1, a}$, Justinas Palisaitis ${ }^{1}$, Muhammad Junaid ${ }^{1}$, Per O. Å. Persson ${ }^{1}$, Jens Jensen ${ }^{1}$, \\ Qing-Xiang Zhao ${ }^{2}$, Lar Hultman ${ }^{1}$, Li-Chyong Chen ${ }^{3}$, Kuei-Hsien Chen ${ }^{3,4}$, Jens Birch ${ }^{1, b}$ \\ ${ }^{1}$ Department of Physics, Chemistry and Biology (IFM), Linköping University, SE-581 83 Linköping, Sweden \\ ${ }^{2}$ Department of Science and Technology (ITN), Linköping University, Campus Norrköping \\ SE-601 74 Norrköping, Sweden \\ ${ }^{3}$ Center for Condensed Matter Sciences, National Taiwan University, Taipei, Taiwan \\ ${ }^{4}$ Institution of Atomic and Molecular Sciences, Academia Sinica, Taipei, Taiwan
}

$\mathrm{Al}_{1-\mathrm{x}} \mathrm{In}_{\mathrm{X}} \mathrm{N}$ heteroepitaxial layers covering the full composition range have been realized by magnetron sputter epitaxy on basal-plane $\mathrm{AlN}, \mathrm{GaN}$, and $\mathrm{ZnO}$ templates at room temperature (RT). Both $\mathrm{Al}_{1-\mathrm{x}} \mathrm{In}_{\mathrm{x}} \mathrm{N}$ single layers and multilayers grown on these isostructural templates show single phase, single crystal wurtzite structure. Even at large lattice mismatch between film and template, for instance InN/AlN ( 13\% mismatch), heteroepitaxy is achieved. However, RT-grown $\mathrm{Al}_{1-\mathrm{x}} \mathrm{In}_{\mathrm{x}} \mathrm{N}$ films directly deposited on non-isostructural $c$-plane sapphire substrate exhibits a polycrystalline structure for all compositions, suggesting that substrate surface structure is important for guiding the initial nucleation. Degradation of $\mathrm{Al}_{1-}$ ${ }_{\mathrm{x}} \mathrm{In}_{\mathrm{x}} \mathrm{N}$ structural quality with increasing indium content is attributed to the formation of more point- and structural defects. The defects result in a prominent hydrostatic tensile stress component, in addition to the biaxial stress component introduced by lattice mismatch, in all RT-grown $\mathrm{Al}_{1-\mathrm{x}} \mathrm{In}_{\mathrm{x}} \mathrm{N}$ films. These effects are reflected in the measured in-plane and out-ofplane strains. The effect of hydrostatic stress is negligible compared to effects of lattice mismatch in high-temperature grown AlN layers thanks to their low amount of defects. We found that Vegards' rule is applicable to determine $x$ in the RT-grown $\mathrm{Al}_{1-\mathrm{x}} \mathrm{In}_{\mathrm{x}} \mathrm{N}$ epilayers if the lattice constants of RT-sputtered AIN and InN films are used instead of those of strainfree bulk materials. 
Keywords: AlInN, InAlN, sputtering, MSE, XRD, TEM, RSM, STEM

Author to whom correspondence should be addressed.

aElectronic mail: hcl@ifm.liu.se

b Electronic mail: jens.birch@ifm.liu.se 


\section{INTRODUCTION}

Since the bandgap of InN was revised to be in the infrared (IR) region $(\sim 0.7 \mathrm{eV})$ [16], $\mathrm{Al}_{1-\mathrm{x}} \operatorname{In}_{\mathrm{x}} \mathrm{N}$ alloys have become very important semiconductors due to their wide bandgap range, covering deep ultraviolet (UV) to IR. Hence, most of the semiconductor optoelectronics can possibly be fabricated from $\mathrm{Al}_{1-\mathrm{x}} \mathrm{In}_{\mathrm{x}} \mathrm{N}$ alloys, such as deep-UV laser diodes, infrared laser diodes, solar cells, high electron mobility transistors, solar-blinded photodetectors [7-14]. However, a wide-range composition immiscibility of the $\mathrm{Al}_{1-\mathrm{x}} \operatorname{In}_{\mathrm{x}} \mathrm{N}$, in the range $0.1<x<0.9$, impedes the fabrication of high-quality devices [15-18]. Phase separation of $\mathrm{Al}_{1-\mathrm{x}} \mathrm{In}_{\mathrm{x}} \mathrm{N}$ in the indium-rich region may occur when the growth temperature is higher than the $\mathrm{InN}$ dissociation temperature of $550{ }^{\circ} \mathrm{C}$ [1-4]. Besides, high temperature growth causes strong thermal stress in epitaxial films. Because the mismatch of thermal expansion coefficient between film and substrate, the in-plane strain of the epitaxial film can be changed from tensile to compressive during the cooling process, resulting in the formation of defects, cracks, and film peel off [19-21]. To suppress phase separation and eliminate thermal stress, films grown at room temperature (RT) are expected to eliminate these handicaps. Nevertheless, low growth temperature usually yields low crystalline quality of the films due to low mobility of adatoms. To overcome this disadvantage, the use of low-energy ion-assitance during epitaxial growth can be adopted to enhance the surface diffusion of adatoms [22-26]. Therefore, magnetron sputter epitaxy (MSE) [15,16,22] is a promising method for growing high-quality $\mathrm{Al}_{1-\mathrm{x}} \mathrm{In}_{\mathrm{x}} \mathrm{N}$ alloys of any composition at very low temperatures thanks to its inherent possibility of utilizing a high flux low-energy ionassistance.

Although RT-grown AlN epilayers have been demonstrated on different substrates, such as $\mathrm{SiC}$ and $\mathrm{ZnO}$, by pulsed laser deposition and pulsed magnetron sputter deposition 
recently [23-25], RT-grown $\mathrm{Al}_{1-\mathrm{x}} \mathrm{In}_{\mathrm{x}} \mathrm{N}$ alloys covering the full composition range have not been explored. It is not sufficient to be limited to AlN as the choice of materials for many kinds of electronics. GaN and its ternaries is an option [27], but introduce additional difficulties in controlling the MSE process due to the low melting point of gallium. Hence, development of single-crystal $\mathrm{Al}_{1-\mathrm{x}} \operatorname{In}_{\mathrm{x}} \mathrm{N}(0 \leq x \leq 1)$ semiconductors is critical to explore more applications. However, growth of high-quality ternary $\mathrm{Al}_{1-\mathrm{x}} \operatorname{In}_{\mathrm{x}} \mathrm{N}$ is more difficult than the binary compounds since $\mathrm{InN}$ and AlN has a large lattice mismatch of 13\%, which is believed to be the reason for the wide solid miscibility gap. Therefore, defects can more easily be generated if adatoms do not occupy the host lattice points. Moreover, the lack of proper lattice-matched substrates also results in the formation of structural defects. The defects create a higher background carrier density and act as trapping centers in the epilayers, which may impede the fabrication of high-performance devices.

In this article, we report a study on single-phase 0002-oriented wurtzite $\mathrm{Al}_{1-\mathrm{x}} \operatorname{In}_{\mathrm{X}} \mathrm{N}(0$ $\leq x \leq 1)$ single layers and multilayers epitaxially grown on isostructural substrates at RT by MSE. From an application point of view, we believe that the potential of fabricating highperformance opto-electronics using low-dislocation-density $\mathrm{AlN}, \mathrm{GaN}$, and $\mathrm{ZnO}$ substrates (commercialized availably) at $\mathrm{RT}$ is very high. Growing metastable $\mathrm{Al}_{1-\mathrm{x}} \mathrm{In}_{\mathrm{x}} \mathrm{N}$ onto temperature sensitive substrates, e.g., indium-tin-oxide glass, plastic etc. by inserting a high quality seed layer is also desirable, which will vastly expand possible applications of group III-nitride semiconductors. For the fundamental physics viewpoint, investigation of the RTheteroepitaxy using isostructural and non-isostructural substrates clarifies that substrate surface structure plays a vital role for the initial nucleation and film growth. Epitaxial film can be grown on isostructural substrates even with a large lattice mismatch between film and substrate. Through reducing lattice mismatch using a designed composition-graded multilayer, the quality of the as-grown film can be further increased. Deviations of lattice parameters 
induced by strains and increase of structural mosaicity in the epilayers, as detected by highresolution x-ray diffraction (HRXRD), are due to the formation of point defects and extended defects which are confirmed by high-resolution transmission electron microscopy (HRTEM), scanning TEM ((S)TEM). Moreover, the applicability of Vegard's rule for these compounds is confirmed.

\section{EXPERIMENTAL DETAILS}

An ultra-high-vacuum (UHV) MSE deposition chamber equipped with two $50 \mathrm{~mm}$ diameter and two $75 \mathrm{~mm}$-diameter targets was utilized to grow $\mathrm{Al}_{1-\mathrm{x}} \operatorname{In}_{\mathrm{x}} \mathrm{N}$ alloys [15-17]. The chamber was evacuated to a base pressure of $<4 \times 10^{-7} \mathrm{~Pa}$ with a combination of turbomolecular and mechanical pumps. High-purity 75 mm-diameter aluminum (99.999\%) and $50 \mathrm{~mm}$-diameter indium $(99.999 \%)$ targets were used to either co-sputter ternary $\mathrm{Al}_{1}$ ${ }_{\mathrm{x}} \mathrm{In}_{\mathrm{x}} \mathrm{N}$ or sputter binary $\mathrm{AlN}$ and $\mathrm{InN}$ films under pure nitrogen ambient, supplied as pure nitrogen gas (99.999999\%) achieved through a getter purifier. The substrates, including $c$ plane sapphire, metal-organic chemical vapor deposition (MOCVD) grown $\mathrm{GaN} / \mathrm{Al}_{2} \mathrm{O}_{3}$ and $\mathrm{ZnO} / \mathrm{Al}_{2} \mathrm{O}_{3}$ templates, were degreased with trichloroethylene, acetone, isopropanol in ultrasonic baths for 5 min each and blown dry with pure nitrogen. High-temperature (HT) $\mathrm{AlN} / \mathrm{Al}_{2} \mathrm{O}_{3}$ templates (HT-AlN) were grown in-situ at $1000{ }^{\circ} \mathrm{C}$ by MSE [8]. Prior to $\mathrm{Al}_{1-\mathrm{x}} \mathrm{In}_{\mathrm{x}} \mathrm{N}$ growth, the sapphire, $\mathrm{GaN}$, and $\mathrm{ZnO}$ substrates were outgassed for $30 \mathrm{~min}$ at 1000, 800, and $700{ }^{\circ} \mathrm{C}$, respectively. All $\mathrm{Al}_{1-\mathrm{x}} \mathrm{In}_{\mathrm{x}} \mathrm{N}$ single layers and multilayers were grown at RT. Typical dc-magnetron powers provided for indium and aluminum targets were of 10 and 50-350 W, respectively, to control the $\mathrm{InN}$ mole fraction. During the sputtering process, a pulsed substrate bias with the peak-to-peak potential of -20 to $+5 \mathrm{~V}$ was applied to the sample holder to enhance growth by low-energy ion assistance. 
The as-grown samples' structures were characterized in a Philips X'pert 4-axis materials research diffractometer with a $\mathrm{Cu}$ lab-source. For high resolution x-ray $20 / \omega$ scan (HRXRD) and rocking curve (XRC) measurement, the beam of pure $\mathrm{Cu} \mathrm{k}_{\alpha 1}(\lambda=0.15406 \mathrm{~nm})$ radiation, produced through a parabolically curved graded multilayer mirror followed by a 2bounce symmetric channel-cut $\mathrm{Ge}(220)$ monochromater, was used as the primary optics, and a 2-bounce asymmetric channel-cut $\mathrm{Ge}(220)$ analyzer was used to collect the diffracted beam. For reciprocal space mapping (RSM), a $1^{\circ}$ slit was used to achieve high intensities in both symmetric 0002 and asymmetric $10 \overline{1} 5$ RSMs. The elemental compositions of the films were determined by Rutherford backscattering spectrometry (RBS) where $2.0 \mathrm{MeV}{ }^{4} \mathrm{He}^{+}$ions was used at an incident angle of $7^{\circ}$ off from the surface normal to avoid channeling effects in the crystalline structure,[28] and back scattered ${ }^{4} \mathrm{He}^{+}$ions were detected at a scattering angle of $172^{\circ}$. Experimental data were analyzed by using the SIMNRA code (version 6.05) [29] to determine the $\mathrm{Al}_{1-\mathrm{x}} \mathrm{In}_{\mathrm{x}} \mathrm{N}$ composition. The concentration of elements as determined from $\mathrm{Al}_{1-}$ ${ }_{\mathrm{x}} \operatorname{In}_{\mathrm{x}} \mathrm{N}$ single layers were used to calibrate the deposition fluxes from the magnetrons at various target powers. Microstructural analyses were performed by HRTEM, selected area electron diffraction (SAED), and (S)TEM using a FEI Tecnai $\mathrm{G}^{2}$ TF 20 UT operated at 200 keV. The cross sectional TEM specimens were prepared by manual grinding and low-angle ion milling until electron transparency.

Figures 1(a) and 1(b) show schematic diagrams of single layers and multilayers $\mathrm{Al}_{1}$ ${ }_{\mathrm{x}} \mathrm{In}_{\mathrm{x}} \mathrm{N}$ thin films, respectively. The growth conditions are listed in Tables 1 and 2, respectively. The single-layer samples consist of single $\mathrm{Al}_{1-\mathrm{x}} \operatorname{In}_{\mathrm{x}} \mathrm{N}$ films grown on HT-AlN templates, which are labeled as $\mathrm{Al}_{0.83} \operatorname{In}_{0.17} \mathrm{~N}, \mathrm{Al}_{0.65} \mathrm{In}_{0.35} \mathrm{~N}, \mathrm{Al}_{0.45} \mathrm{In}_{0.55} \mathrm{~N}, \mathrm{Al}_{0.28} \mathrm{In}_{0.82} \mathrm{~N}$, and $\mathrm{InN}$. The multilayer (ML) samples consist of multi $\mathrm{Al}_{1-\mathrm{x}} \mathrm{In}_{\mathrm{x}} \mathrm{N}$ layers with increasing indium contents, from pure $\mathrm{AlN}$ or $\mathrm{Al}_{0.83} \mathrm{In}_{0.17} \mathrm{~N}$ to pure $\mathrm{InN}$, grown on substrates of sapphire, HT-AlN, GaN, and $\mathrm{ZnO}$ templates, in this work denoted ML-sapphire, ML-AlN, ML-GaN, and ML-ZnO, 
respectively. All samples were grown at RT except for a thicker 360-nm HT-AlN grown at $1000{ }^{\circ} \mathrm{C}$, which exhibited lattice parameters equal to those of bulk AlN [20], $c_{o}^{A I N}=0.498$ $\mathrm{nm}$ and $a_{o}^{A l N}=0.311 \mathrm{~nm}$, as determined by RSM, and was used as a reference sample for strain determination in the seed layer. The compositions and thicknesses of the $\mathrm{Al}_{1-\mathrm{x}} \mathrm{In}_{\mathrm{x}} \mathrm{N}$ films shown in Table 1 were determined by RBS and TEM, respectively. Apparently, the aluminum content increases monotonically with magnetron power enabling a compositional control. For the multilayer samples, the magnetron powers of each layer are corresponding to those of single layers, shown in Table 1, with the sequence of $A l N$ to $\mathrm{Al}_{1-\mathrm{x}} \mathrm{In}_{\mathrm{x}} \mathrm{N}$ multilayer to InN. Herein, the AlN layer was grown at RT.

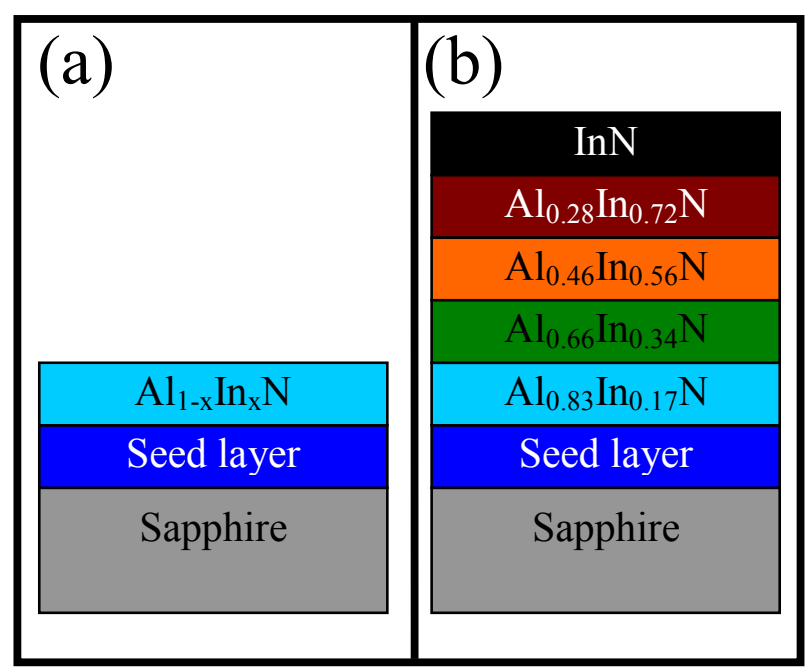

Fig. 1. Schematic diagrams of (a) $\mathrm{Al}_{1-\mathrm{x}} \mathrm{In}_{\mathrm{x}} \mathrm{N}$ single layer grown on a template with a HT-AIN seed layer, and (b) $\mathrm{Al}_{1-\mathrm{x}} \mathrm{In}_{\mathrm{x}} \mathrm{N}$ multilayer grown on different templates, HT-AlN seed layer grown by MSE, GaN and $\mathrm{ZnO}$ seed layers grown by MOCVD. 
Table 1 Growth conditions of RT-grown $\mathrm{Al}_{1-\mathrm{x}} \mathrm{In}_{\mathrm{X}} \mathrm{N}(0 \leq x \leq 1)$ single layers (except samples HT-AlN-R and HT-AlN, which were grown at $1000{ }^{\circ} \mathrm{C}$ ). All samples were grown on a $\sim 40$ nm thick HT-AIN seed layer.

\begin{tabular}{ccccc}
\hline \hline Sample & $\begin{array}{c}\text { Al power } \\
(\mathrm{W})\end{array}$ & $\begin{array}{c}\text { In power } \\
(\mathrm{W})\end{array}$ & $\begin{array}{c}\text { Composition, } \\
x\end{array}$ & $\begin{array}{c}\text { Thickness } \\
(\mathrm{nm})\end{array}$ \\
\hline $\mathrm{HT}-\mathrm{AlN}-\mathrm{R}$ & 350 & 0 & 0 & 360 \\
$\mathrm{HT}-\mathrm{AlN}$ & 350 & 0 & 0 & 40 \\
$\mathrm{Al}_{0.83} \mathrm{In}_{0.17} \mathrm{~N}$ & 350 & 10 & 17 & 132 \\
$\mathrm{Al}_{0.66} \mathrm{In}_{0.34} \mathrm{~N}$ & 200 & 10 & 34 & 88 \\
$\mathrm{Al}_{0.46} \mathrm{In}_{0.56} \mathrm{~N}$ & 100 & 10 & 56 & 100 \\
$\mathrm{Al}_{0.28} \mathrm{In}_{0.72} \mathrm{~N}$ & 50 & 10 & 72 & 100 \\
$\mathrm{InN}$ & 0 & 10 & 100 & 87 \\
\hline \hline
\end{tabular}

Table 2 Templates used for RT-grown $\mathrm{Al}_{1-\mathrm{x}} \mathrm{In}_{\mathrm{x}} \mathrm{N}(0 \leq x \leq 1)$ multilayers. The growth conditions of all subsequent layers were grown as the same as single layers listed in Table 1.

\begin{tabular}{cccc}
\hline \hline Sample & Template & First layer & subsequent layers \\
\hline ML-sapphire & $\mathrm{Al}_{2} \mathrm{O}_{3}$ & $\mathrm{Al}_{0.83} \mathrm{In}_{0.17} \mathrm{~N}$ & $\mathrm{Al}_{0.66} \mathrm{In}_{0.34} \mathrm{~N}$ to InN (4 layers) \\
ML-AlN & $\mathrm{HT}-\mathrm{AlN} / \mathrm{Al}_{2} \mathrm{O}_{3}$ & $\mathrm{Al}_{0.83} \mathrm{In}_{0.17} \mathrm{~N}$ & $\mathrm{Al}_{0.66} \mathrm{In}_{0.34} \mathrm{~N}$ to InN (4 layers) \\
ML-GaN & $\mathrm{GaN} / \mathrm{Al}_{2} \mathrm{O}_{3}$ & RT-AlN & $\mathrm{Al}_{0.83} \mathrm{In}_{0.17} \mathrm{~N}$ to InN (5 layers) \\
ML-ZnO & $\mathrm{ZnO} / \mathrm{Al}_{2} \mathrm{O}_{3}$ & RT-AlN & $\mathrm{Al}_{0.83} \mathrm{In}_{0.17} \mathrm{~N}$ to InN (5 layers) \\
\hline \hline
\end{tabular}

\section{RESULTS AND DISCUSSION}

All $\mathrm{Al}_{1-\mathrm{x}} \mathrm{In}_{\mathrm{x}} \mathrm{N}$ single layers show shiny surfaces and are transparent with colors changing from colorless (transparent), to orange, to brown, and to dark brown with increasing indium content, which implies the change of the energy band gaps from UV to near IR. However, the effect of point and structural defects in the $\mathrm{Al}_{1-\mathrm{x}} \mathrm{In}_{\mathrm{x}} \mathrm{N}$ films can not be ruled out as a reason for the colorless to color transition owing to possible impurity/defect band 
absorption in the visible region. Since the carrier density of pure $\mathrm{InN}$ is still around $10^{20} \mathrm{~cm}^{-3}$, as determined by Hall measurements (not reported here), the absorption edge would be close to $1.6 \mathrm{eV}$ owing to the Burstein-Moss (band filling) effect [1-3]. Hence, the $\mathrm{InN}$ film is expected to appear dark brown rather than black.

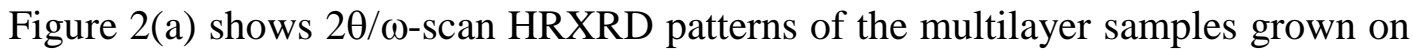
the different templates. The film which was directly deposited onto sapphire (sample MLSapphire) can barely be detected by HRXRD. This material turned out to be polycrystalline with no epitaxial relationship, as determined by a combination of XRD techniques. When a

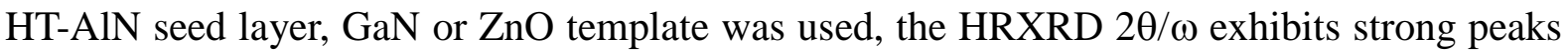
from each of the individual layers. All $\mathrm{Al}_{1-\mathrm{x}} \mathrm{In}_{\mathrm{x}} \mathrm{N}$ layers exhibit a single phase with growth orientation along the $c$-axis direction. Other crystalline orientations were not detected in longrange scans, even in low-resolution which allows for detection of polycrystalline materials. Apparently, the substrate structure is seen to play a very important role in the subsequent film growth. Although the atomic surface arrangement of $c$-plane sapphire has the same hexagonal geometry as wurtzite structure, the $\mathrm{Al}_{1-\mathrm{x}} \mathrm{In}_{\mathrm{x}} \mathrm{N}$ films did not grow epitaixally on sapphire. This growth behavior is completely different from HT growth where heteroepitaxy of III-N semiconductors on sapphire is commonplace. This is due to the relatively low kinetic energy at RT for adatoms to overcome the thermal barrier to reach the most stable sites. Therefore, the substrate surface structure (surface terminated layers) has to be considered as the reason of the growth difference. The wurtzite structure has a hexagonal close-packed (hcp) type $(A B A B A B \ldots)$ stacking sequence with identical atomic arrangement for $A$ and $B$ layers. No matter if the nuclei occupy $A$ or $B$ terminated layers, the in-plane growth orientation and lattice-mismatch to the underneath layers of the nuclei are the same. Hence, the subsequently grown grains on these nuclei can all be $c$-axis oriented, but will eventually form domains defined by stacking mismatch boundaries. In contrast, sapphire is a rhombohedral structure 

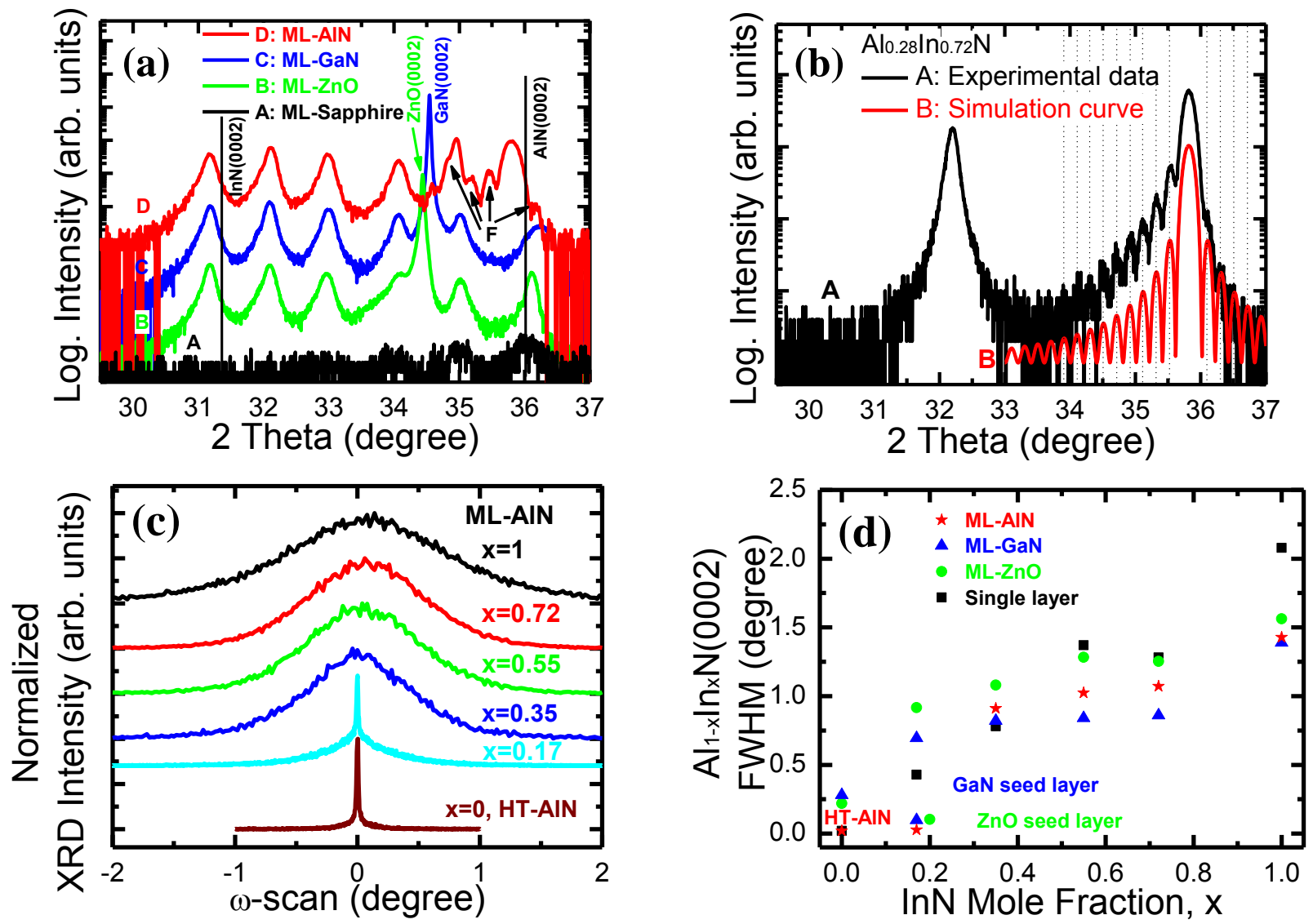

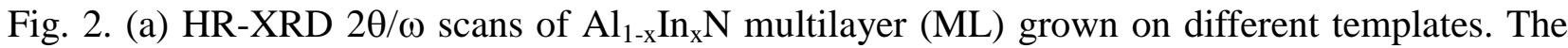
thickness fringes are indicated by ' $\mathrm{F}$ ' with arrows. (b) Top curve: $2 \theta / \omega$ scan of an $\mathrm{Al}_{0.28} \mathrm{In}_{0.72} \mathrm{~N}$ single layer grown on HT-AIN layer. Bottom curve: Simulated curve of HT-AlN layer on sapphire. The dot lines are corresponding to the peak position of each thickness fringes in the simulated curve. (c) The 0002 reflections of $\mathrm{Al}_{1-\mathrm{x}} \mathrm{In}_{\mathrm{x}} \mathrm{N}$ ML's rocking curves measured by sample ML-AlN. (d) FWHM of rocking curves. The InN mole fraction was determined from $\mathrm{Al}_{1-\mathrm{x}} \mathrm{In}_{\mathrm{x}} \mathrm{N}$ single layers by RBS. 
and does not possess the same stacking as wurtzite although it is often expressed in terms of hexagonal parameters. The structure viewed along the $c$ axis shows hexagonal lattice, and the layer sequence follows with one O layer sandwiched in-between two Al layers [30-32]. The O layers follow approximately hcp-type stacking and Al layers follow face-centered cubic type $(a b c a b c \ldots)$ stacking. Since it is difficult to obtain an ideal well-terminated sapphire surface, the nuclei, which react to the $\mathrm{Al}$ and $\mathrm{O}$ terminated layers, will have different in-plane orientations $\left(30^{\circ}\right.$ rotation) and lattice mismatches, for instance -35 and $+13 \%$ for AlN on the $\mathrm{Al}$ and $\mathrm{O}$ terminated layers of the substrate, respectively. At low temperatures with strongly limited adatom mobility, this will limit the size of the subsequently grown grains in the film and new growth orientations, rather than $c$-axis, can develop and form polycrystalline structures or generally poor crystallinity.

The strain state of the sputtered films is discussed by comparing to the strain-free bulk materials $[8,33,34]$. Two indicating lines at $31.4^{\circ}$ and $36.0^{\circ}$ are plotted in the Fig. 2(a) to indicate the 0002 reflections of relaxed, stoichiometric $\mathrm{InN}$ and AlN, respectively. The XRD patterns show clear shifts of the AlN and InN reflections, possibly due to out-of-plane tensile strain, along the $c$-direction. Interestingly, the AlN peak shifts are in opposite directions depending on substrate material, indicating compressive and tensile strain along the $c$ direction, out-of-plane, for growth on $\mathrm{GaN}$ or $\mathrm{ZnO}$ and HT-AIN, respectively. However, the subsequent layers are located at the same positions except for the first layer of the $\mathrm{Al}_{0.83} \operatorname{In}_{0.17} \mathrm{~N}$, which apparently is strained in the same manner as the initial AlN layer. This result implies that the strain state of the $\mathrm{Al}_{1-\mathrm{x}} \mathrm{In}_{\mathrm{x}} \mathrm{N}$ layers subsequent to the second layer, may be relaxed. Nevertheless, all InN-peaks are shifted toward lower $2 \theta$ angles as compared to strain-free bulk InN, indicating $c$-plane lattice expansions, independent of substrate. Such a positive out-of-plane strain may be an elastic reaction (aka. Poisson reaction) to an in-plane compressive biaxial stress (due to the effects of lattice and/or thermal expansion coefficient 
mismatches) or an effect of a hydrostatic (spherical) stress component in the lattice (caused for example by point defects), or a combination of the two. The extra peaks (indicated by ' $F$ ') appearing around the first $\mathrm{Al}_{1-\mathrm{x}} \mathrm{In}_{\mathrm{x}} \mathrm{N}$ layer peak in the ML-AlN sample are thickness fringes from the HT-AlN due to the high-quality film with flat interfaces, as has previously been

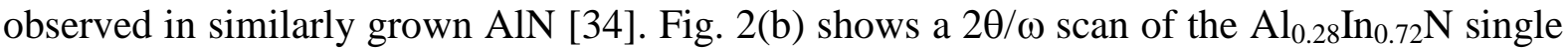
layer on HT-AlN exhibiting the thickness fringes of the HT-AlN extending about $-2^{\circ}$ from the 0002 peak. A simulated curve generated by the Philips X'pert Epitaxy software shows that all fringes are well matched to the experimental data, assuming a thickness of the HT-AlN of 37 nm and $\sim 1 \%$ in-plane compressive strain. The observed transverse lattice expansion, as reflected in the lower 0002 peak position compared to bulk AlN, may be a result of the elastic Poisson reaction. The mosaic tilts of those films were further characterized by XRC. Fig. 2(c) shows the rocking curves of the ML-AlN sample. The HT-AlN seed layer has an extremely narrow full-width-at-half-maximum (FWHM) of $0.02^{\circ}(72 \operatorname{arcsec})$, which implies a very high quality of the layer. The following RT-grown $\mathrm{Al}_{0.83} \mathrm{In}_{0.17} \mathrm{~N}$ layer also shows a narrow $\mathrm{FWHM}$ with a broad base profile. By fitting the curve to a two-peak Gaussian function, a narrow component with FWHM $=0.02^{\circ}$ and a broad part with a FWHM of $0.54^{\circ}$ are de-convoluted from each other. Hence, we conclude that the peak shape is attributed to a superposition of the narrow HT-AlN thickness fringes and the broader $\mathrm{Al}_{0.83} \operatorname{In}_{0.17} \mathrm{~N}$ base profile. With increasing indium content, the FWHMs of the $\mathrm{Al}_{1-\mathrm{x}} \mathrm{In}_{\mathrm{x}} \mathrm{N}$ layers become broader, reaching $1.43^{\circ}$ for the top InN layer. The FWHMs of all samples' rocking curves are plotted in Fig. 2(d). Both single layers and multilayers of $\mathrm{Al}_{1-\mathrm{x}} \operatorname{In}_{\mathrm{x}} \mathrm{N}(0 \leq x \leq 1)$ show the same trend, where the FWHM increases with increasing indium content. Moreover, the FWHMs of highindium-content $\mathrm{Al}_{1-\mathrm{x}} \mathrm{In}_{\mathrm{x}} \mathrm{N}$ single layers are higher than from the corresponding compositions in the multilayer although they are grown on the high-quality HT-AlN seed layer. This difference shows that the lattice mismatch is a dominant factor in affecting the crystalline 
quality rather than the previous layer's quality. For instance, InN, when directly deposited onto HT-AIN (with $~ 13 \%$ lattice mismatch [35]) has an XRC FWHM of $2.08^{\circ}$ but only $1.43^{\circ}$ if the $\mathrm{InN}$ is deposited on the lower quality $\mathrm{Al}_{0.28} \mathrm{In}_{0.78} \mathrm{~N}$ layer with only $3 \%$ mismatch. Hence, minimizing lattice mismatch is important in isostructural RT heteroepitaxy for obtaining group III-N ternary material of highest possible structural quality.

Figure 3 shows RSMs around the symmetric 0002 and asymmetric $10 \overline{15}$ reflections of samples ML-AlN [Fig. 3(a) and 3(b)], ML-GaN [Fig. 3(c) and 3(d)], and ML-ZnO [Fig. 3(e) and 3(f)], where a $\log _{2}$ scale of the contour levels has been used. All symmetric 0002 maps show well aligned contours along the transverse scattering vector $\left(\mathrm{Q}_{\mathrm{z}}\right)$ direction for all $\mathrm{Al}_{1-\mathrm{x}} \operatorname{In}_{\mathrm{x}} \mathrm{N}$ layers. The centers of the contours are located at almost zero lateral scattering vector $\left(Q_{x}\right)$ except for the top InN layers which show slight misalignments, indicating highly $c$-axis orientated growth of the films. In the asymmetric $10 \overline{1} 5$ maps, the peaks can be seen to be well aligned along the $2 \theta / \omega$-scan direction, i.e., radially in reciprocal space except for the RT-AlN layers. Since AlN has the lattice mismatches of -2.3 and $-4.3 \%$ to $\mathrm{GaN}$ and $\mathrm{ZnO}$, respectively, the RT-grown $\mathrm{AlN}$ layers on $\mathrm{GaN}$ and $\mathrm{ZnO}$ templates exhibit in-plane strains,

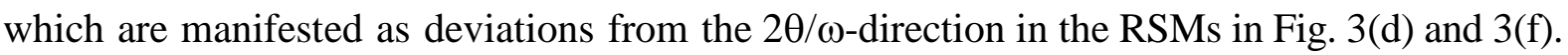
In addition, only six peaks with 60-degree intervals were observed during azimuthal $\varphi$ scans recording the $10 \overline{15}$ reflections of any of the layers (not shown here), showing that the layers were grown in a highly oriented fashion with the epitaxial relationships of $(0001)_{\mathrm{f}} \|(0001)_{\mathrm{s}}$ and $[10 \overline{10}]_{\mathrm{f}} \|[10 \overline{1} 0]_{\mathrm{s}}$. From the above results, we can conclude that the $\mathrm{Al}_{1-\mathrm{X}} \mathrm{In}_{\mathrm{X}} \mathrm{N}$ layers were grown epitaxially on isostructural templates at RT. Next, the peak broadenings seen in both symmetric and asymmetric RSMs are analyzed in more details. The broadening that can be observed for the 0002 peaks, ellipsoidal contours, of the HT-AlN, GaN, and $\mathrm{ZnO}$ templates extend in the direction of the Ewald's sphere and is an artifact of using a receiving slit 

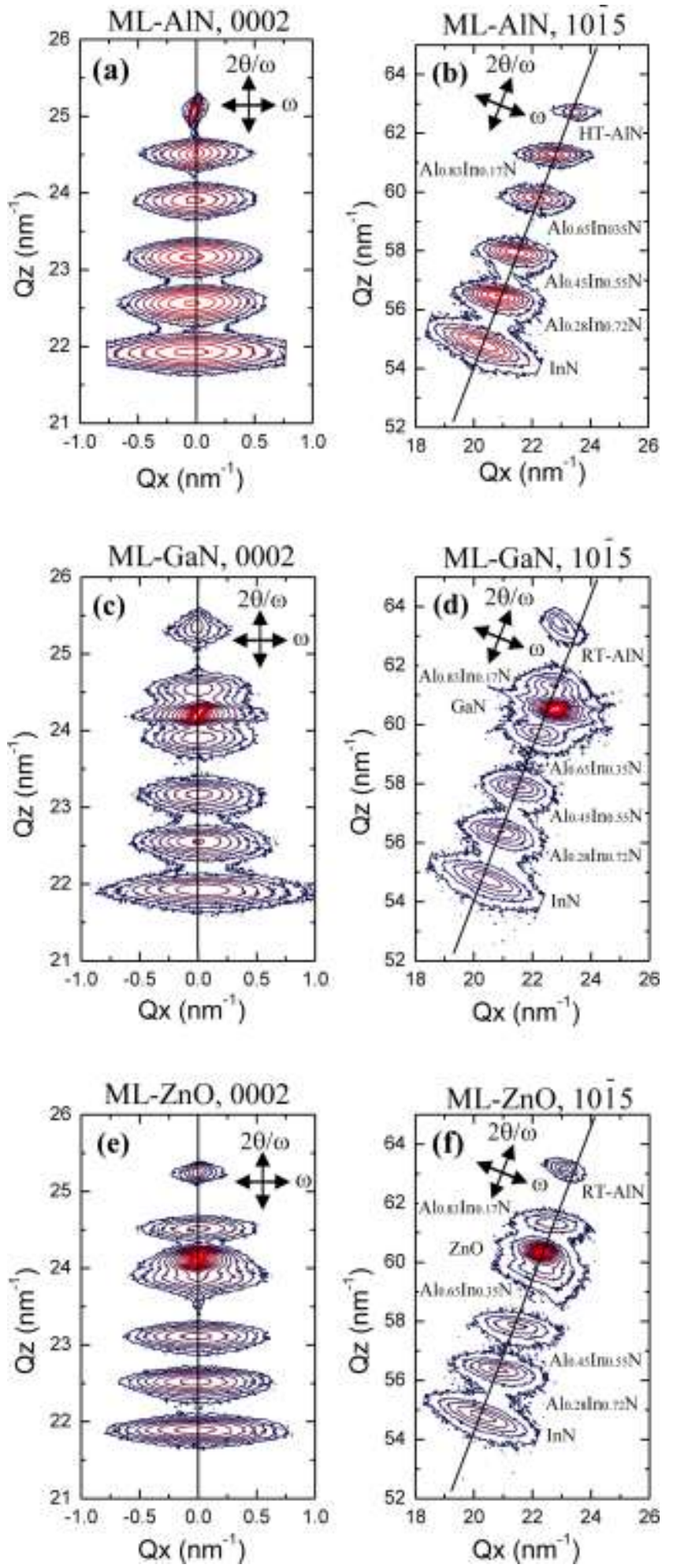

Fig. 3. RSMs around the symmetric 0002 and the asymmetric $10 \overline{1} 5$ reflections of $\mathrm{Al}_{1-\mathrm{x}} \mathrm{In}_{\mathrm{x}} \mathrm{N}$ multilayers: (a) and (b) ML-AlN, (c) and (d) ML-ZnO, and (e) and (f) ML-GaN. Note: Logarithmic scale contour levels of RSMs were used in order to reduce the influence of strong intensity from $\mathrm{GaN}$ and $\mathrm{ZnO}$ templates. These maps were constructed with 2-axes $2 \theta / \omega$ and $\omega$ scans. The axes of $Q_{z}$ and $Q_{x}$ are transverse and lateral scattering vectors, respectively. The length of $Q$ is equal to $2 \pi / d$, where $d$ is the interplanar lattice spacing. 
optimized for the less perfect $A 1_{1-x} I_{x} N$ layers. The first layers, i.e., $A 1 N$ or $A 1_{0.83} \operatorname{In}_{0.17} \mathrm{~N}$, also give raise to tilted ellipsoidal contours, indicating a high crystal quality. With increasing indium content, the 0002 peaks become broader and broader, implying a trend of degrading crystalline quality. In the asymmetric maps, the broadening can be further separated into to two types. One type is parallel to the lateral $\mathrm{Q}_{\mathrm{x}}$ direction and is observed for the high $\mathrm{Al}$ content layers, $x \leq 0.17$. This implies a short lateral coherence length owing either to growth with a characteristic column or domain width and/or the existence of laterally repeated structural defects such as misfit dislocations. The other type of broadening, which is parallel to the $\omega$-scan direction and observed for high indium content layers, is attributed to mosaic tilts in the crystal lattice or a generally high amount of dislocations, grain boundaries, and/or point defects $[6,36]$. The maps show that higher indium content $\mathrm{Al}_{1-\mathrm{x}} \mathrm{In}_{\mathrm{x}} \mathrm{N}$ layer contains more structural defects of the latter type.

Figure 4(a) shows $c$ and $a$ lattice constants of $\mathrm{Al}_{1-\mathrm{x}} \operatorname{In}_{\mathrm{x}} \mathrm{N}$ single layers and multilayers, extracted from RSMs, plotted as a function of InN mole fraction, as determined by RBS. The black solid and red dashed lines indicate strain-free lattice constants of $\mathrm{Al}_{1-\mathrm{x}} \mathrm{In}_{\mathrm{x}} \mathrm{N}, c$ and $a$, respectively, as predicted by Vegard's law using bulk AlN and InN lattice constants [20,21,35]. The experimental values of both $c$ and $a$ increase with increasing indium concentration and are longer than the strain-free lattice constants for all $x>0$, revealing positive in-plane and out-of-plane strains. Only AlN layers show opposite in-plane and outof-plane strain states. In addition, the RT-sputtered InN layers have $a^{\operatorname{InN}}=0.356-0.358 \mathrm{~nm}$ and $c^{\operatorname{InN}}=0.573-0.574 \mathrm{~nm}$, which are longer than the strain-free $a_{o}^{\operatorname{InN}}=0.354 \mathrm{~nm}$ and $c_{o}^{I n N}=0.571 \mathrm{~nm}[20,21]$, indicating that the $\mathrm{InN}$ plays the main role for producing the positive strains in sputtered $\mathrm{Al}_{1-\mathrm{x}} \mathrm{In}_{\mathrm{x}} \mathrm{N}$ films. Although the positive strains are presented in all $\mathrm{Al}_{1-\mathrm{x}} \operatorname{In}_{\mathrm{x}} \mathrm{N}$ layers $(x>0)$, the $c / a$ ratios are still kept in the range of 1.600 to 1.613 , which is in 
the range of strain-free AlN, 1.601, and $\mathrm{InN}, 1.613$ [20,35]. In the present case, if the nominal bulk strain-free $\mathrm{InN}$ and $\mathrm{AlN}$ lattice constants are used to calculate the composition in the $\mathrm{Al}_{1-}$. ${ }_{x} \operatorname{In}_{x} \mathrm{~N}(x>0)$ epilayers, an over estimation of the $\mathrm{InN}$ mole fraction is always obtained. In contrast, using the lattice constants of RT-sputtered InN and AlN, grown under the same conditions as the ternaries, the composition calculated from RSMs have a better match to the RBS result. Thus, we found that Vegard's rule, i.e., estimating the composition by linear interpolation of lattice parameters, is again applicable for all $x$. Hence, the strain state has to be taken into account for the composition estimation using XRD.
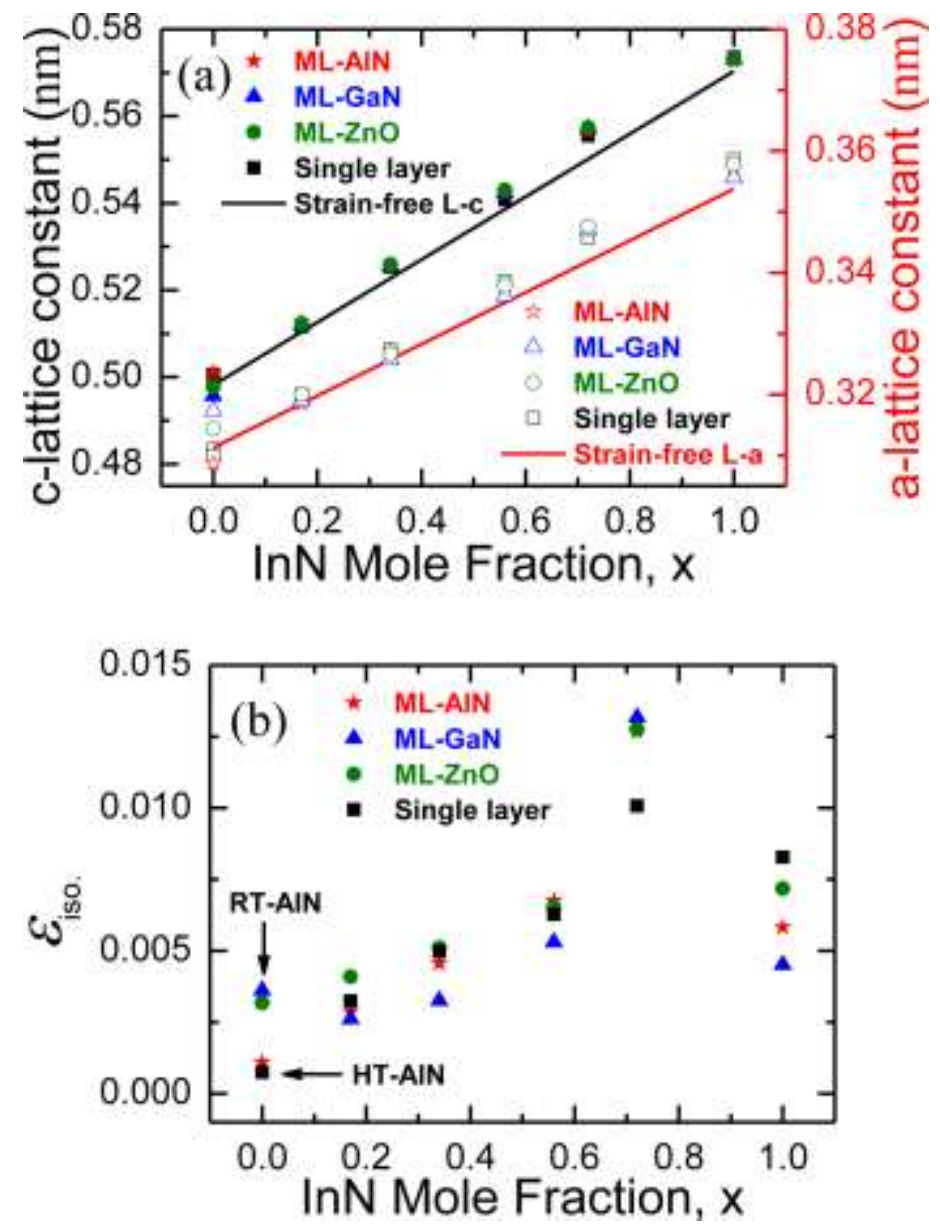

Fig. 4. (a) Lattice constants of $\mathrm{Al}_{1-\mathrm{x}} \mathrm{In}_{\mathrm{x}} \mathrm{N}$ single layers and multilayer extracted from RSMs plotted as the InN mole fraction measured by RBS from $\mathrm{Al}_{1-\mathrm{x}} \mathrm{In}_{\mathrm{x}} \mathrm{N}$ single layers. The solid and dash lines indicate ideal $\mathrm{Al}_{1-\mathrm{x}} \mathrm{In}_{\mathrm{x}} \mathrm{N}$ lattice constants of $c$ and $a$, respectively, and its relationship determined by Vegard's law from bulk AlN and InN lattice constants. $L-c$ and $L$ $a$ are lattice constants of $c$ and $a$, respectively. (b) The calculated isotropic strain components, $\varepsilon_{\text {iso. }}(x)$, plotted as function of $\mathrm{InN}$ mole fraction. 
To clarify the strain state in the $\mathrm{Al}_{1-\mathrm{x}} \mathrm{In}_{\mathrm{x}} \mathrm{N}$ layers, in-plane, $\varepsilon_{1}(x)$, and out-of-plane, $\varepsilon_{3}(x)$, strains are calculated by the following equations using the compositions determined from RBS and lattice constants, $a$ and $c$, measured from RSMs.

$$
\begin{aligned}
& \varepsilon_{1}(x)=1-\frac{x\left(a_{o}^{I n N}-a_{o}^{A l}\right)+a_{o}^{A l \Lambda}}{a} \\
& \varepsilon_{3}(x)=1-\frac{x\left(c_{o}^{I n N}-c_{o}^{A l}\right)+c_{o}^{A l N}}{c}
\end{aligned}
$$

If the film is under the elastic Poisson deformation with biaxial stress only, the ratio of $\frac{\varepsilon_{3}(x)}{\varepsilon_{1}(x)}$ is expected to be equal to $-\frac{2 C_{13}(x)}{C_{33}(x)}$. Since the stiffness constants $C_{i j}(x)$ are dependent on $c / a$ ratio as well as used calculation theories [37-39], making it difficult to present exact Poisson deformation, we adopt reliable stiffness constants calculated by Manuel and Morales et al. $[38,39]$ using the method of Shapiro-Wilk statistical normality test for AlN and InN. There, the $C_{13}(x)$ and $C_{33}(x)$ are derived from Vegard's rule using stiffness constants of $\mathrm{AlN}, C_{13}^{A l N} \approx 107$ and $C_{33}^{A l N} \approx 404 \mathrm{GPa}$, and $\mathrm{InN}, C_{13}^{\operatorname{InN}} \approx 85$ and $C_{33}^{\operatorname{InN}} \approx 237 \mathrm{GPa}$. The calculated results show that all $\mathrm{Al}_{1-\mathrm{x}} \mathrm{In}_{\mathrm{x}} \mathrm{N}(x>0)$ layers have positive strain ratios, indicating a predominantly hydrostatic internal stress, leading to a major isotropic strain component, in addition to a minor effect of a Poisson reaction, caused by a biaxial in-plane stress component, in the grown films. Only HT-AIN has a ratio of -0.69 , which is close to the expected value of -0.53 , but it is still not a pure Poisson deformation only. Therefore, the measured total strain should contain all strain components and can be treated as the sum of the strain components: pure in-plane, $\varepsilon_{1}^{*}(x)$, and out-of-plane, $\varepsilon_{3}^{*}(x)$, strains, and isotropic strain component due to hydrostatic stress, $\varepsilon_{\text {iso. }}(x)[40,41]$.

$$
\varepsilon_{1}(x)=\varepsilon_{1}^{*}(x)+\varepsilon_{i s . d}(x)
$$




$$
\varepsilon_{3}(x)=\varepsilon_{3}^{*}(x)+\varepsilon_{i s . d}(x)
$$

The isotropic strain component can be deconvoluted using Eqs. (1) and (2) and represented by Eq. (5),

$$
\varepsilon_{i s .}(x)=\frac{2 C_{13}(x) \varepsilon_{1}(x)+C_{33}(x) \varepsilon_{3}(x)}{2 C_{13}(x)+C_{33}(x)}
$$

Table 3 shows clear isotropic strain component presented dominantly in all $\mathrm{Al}_{1-\mathrm{x}} \mathrm{In}_{\mathrm{x}} \mathrm{N}$ single layers. In contrast, the strain state of the HT-AlN seed layer is dominated by the Poisson deformation. Fig. 4(b) shows the isotropic strain component plotted as function of InN mole fraction for all samples. Obviously, the isotropic strain component is presented prominently in all $\mathrm{RT}-\mathrm{Al}_{1-\mathrm{x}} \mathrm{In}_{\mathrm{x}} \mathrm{N}$ layers, but not HT-AlN layers. Although the scatter data increases with increasing indium concentration due to the broader peaks, shown in Fig. 3, the trend of the isotropic strain component still shows a clear increase with increasing $\mathrm{InN}$ mole fraction. The high value for the $\mathrm{Al}_{1-\mathrm{x}} \mathrm{In}_{\mathrm{x}} \mathrm{N}$ layers with $0.72 \mathrm{InN}$ mole fraction may be due to slight run-torun fluctuations in the growth conditions between the single layer depositions, used for RBS measurement, and the multilayer depositions.

Table 3 Strain state of the $\mathrm{Al}_{1-\mathrm{x}} \mathrm{In}_{\mathrm{x}} \mathrm{N}$ single layers. Measured in-plane, $\varepsilon_{1}(x)$, and out-ofplane, $\varepsilon_{3}(x)$, strains are calculated by using experimental values of both $c$ and $a$, as well as compositions determined from RBS. The $\frac{\varepsilon_{3}^{*}(x)}{\varepsilon_{1}^{*}(x)}$ ratios are calculated from theoretical values, $-\frac{2 C_{13}(x)}{C_{33}(x)}$. The calculated isotropic strain component shown in all $\mathrm{Al}_{1-\mathrm{x}} \operatorname{In}_{\mathrm{x}} \mathrm{N}$ layers are much larger than HT-AlN.

\begin{tabular}{cccccccc}
\hline \hline & $a(\mathrm{~nm})$ & $c(\mathrm{~nm})$ & $\begin{array}{c}\text { In-plane } \\
\text { strain, } \\
\varepsilon_{1}(x)\end{array}$ & $\begin{array}{c}\text { Out-of-plane } \\
\text { strain, } \varepsilon_{3}(x)\end{array}$ & $\frac{\varepsilon_{3}(x)}{\varepsilon_{1}(x)}$ & $\frac{\varepsilon_{3}^{*}(x)}{\varepsilon_{1}^{*}(x)}$ & $\begin{array}{c}\text { Isotropic } \\
\text { strain, } \\
\varepsilon_{\text {iso. }}(x)\end{array}$ \\
\hline $\mathrm{HT}-\mathrm{AlN}$ & 0.3089 & 0.5005 & -0.0071 & 0.0048 & -0.6733 & -0.5297 & 0.0007 \\
$\mathrm{Al}_{0.83} \mathrm{In}_{0.17} \mathrm{~N}$ & 0.3200 & 0.5116 & 0.0050 & 0.0023 & 0.4573 & -0.5501 & 0.0033 \\
$\mathrm{Al}_{0.66} \mathrm{In}_{0.34} \mathrm{~N}$ & 0.3274 & 0.5253 & 0.0052 & 0.0049 & 0.9273 & -0.5738 & 0.0050 \\
$\mathrm{Al}_{0.44} \mathrm{In}_{0.56} \mathrm{~N}$ & 0.3386 & 0.5408 & 0.0103 & 0.0039 & 0.3783 & -0.6110 & 0.0063 \\
$\mathrm{Al}_{0.28} \mathrm{In}_{0.72} \mathrm{~N}$ & 0.3458 & 0.5555 & 0.0110 & 0.0094 & 0.8492 & -0.6441 & 0.0100 \\
$\mathrm{InN}$ & 0.3585 & 0.5736 & 0.0126 & 0.0052 & 0.4167 & -0.7203 & 0.0083 \\
\hline \hline
\end{tabular}




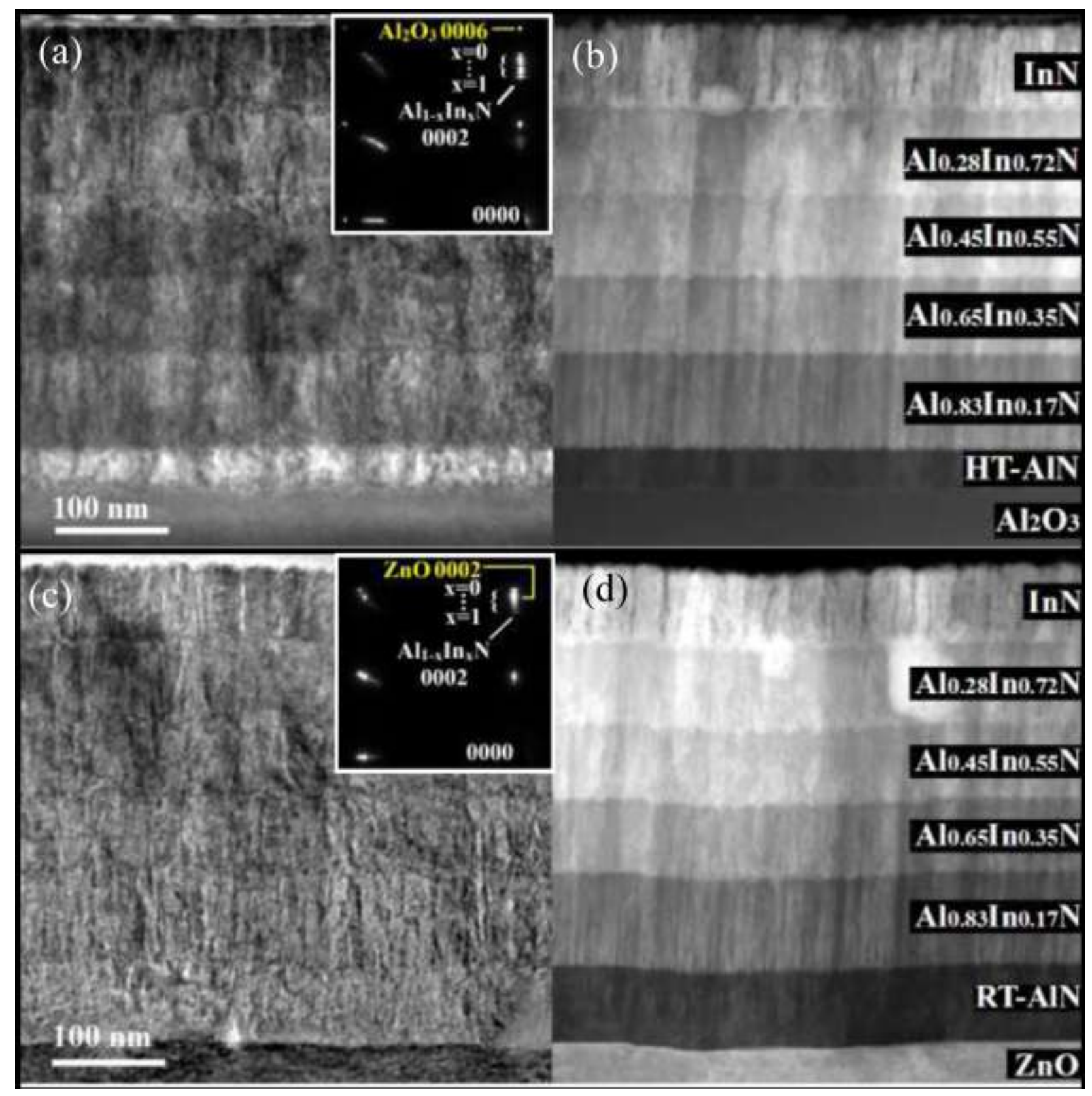

Fig. 5. Cross-sectional bright-field TEM and STEM image of $\mathrm{Al}_{1-\mathrm{x}} \operatorname{In}_{\mathrm{x}} \mathrm{N}$ multilayers grown on HT-AlN and ZnO seed layer: (a) and (b) ML-AlN and (c) and (d) ML-ZnO. The insets of Fig. 5(a) and 5(c) are the corresponding SAED patterns taken from samples ML-AlN and ML$\mathrm{ZnO}$, respectively. The corresponding zone axes of the film (all $\mathrm{Al}_{1-\mathrm{x}} \mathrm{In}_{\mathrm{x}} \mathrm{N}(0 \leq x \leq 1)$ layers) and substrate are, $\mathrm{Al}_{1-\mathrm{x}} \mathrm{In}_{\mathrm{x}} \mathrm{N}[1 \overline{1} 00]$ and $\mathrm{Al}_{2} \mathrm{O}_{3}$ [11 $\left.\overline{2} 0\right]$, and $\mathrm{Al}_{1-\mathrm{x}} \mathrm{In}_{\mathrm{x}} \mathrm{N}[1 \overline{1} 00]$ and $\mathrm{ZnO}[1 \overline{1} 00]$, for sapphire and $\mathrm{ZnO}$, respectively. 


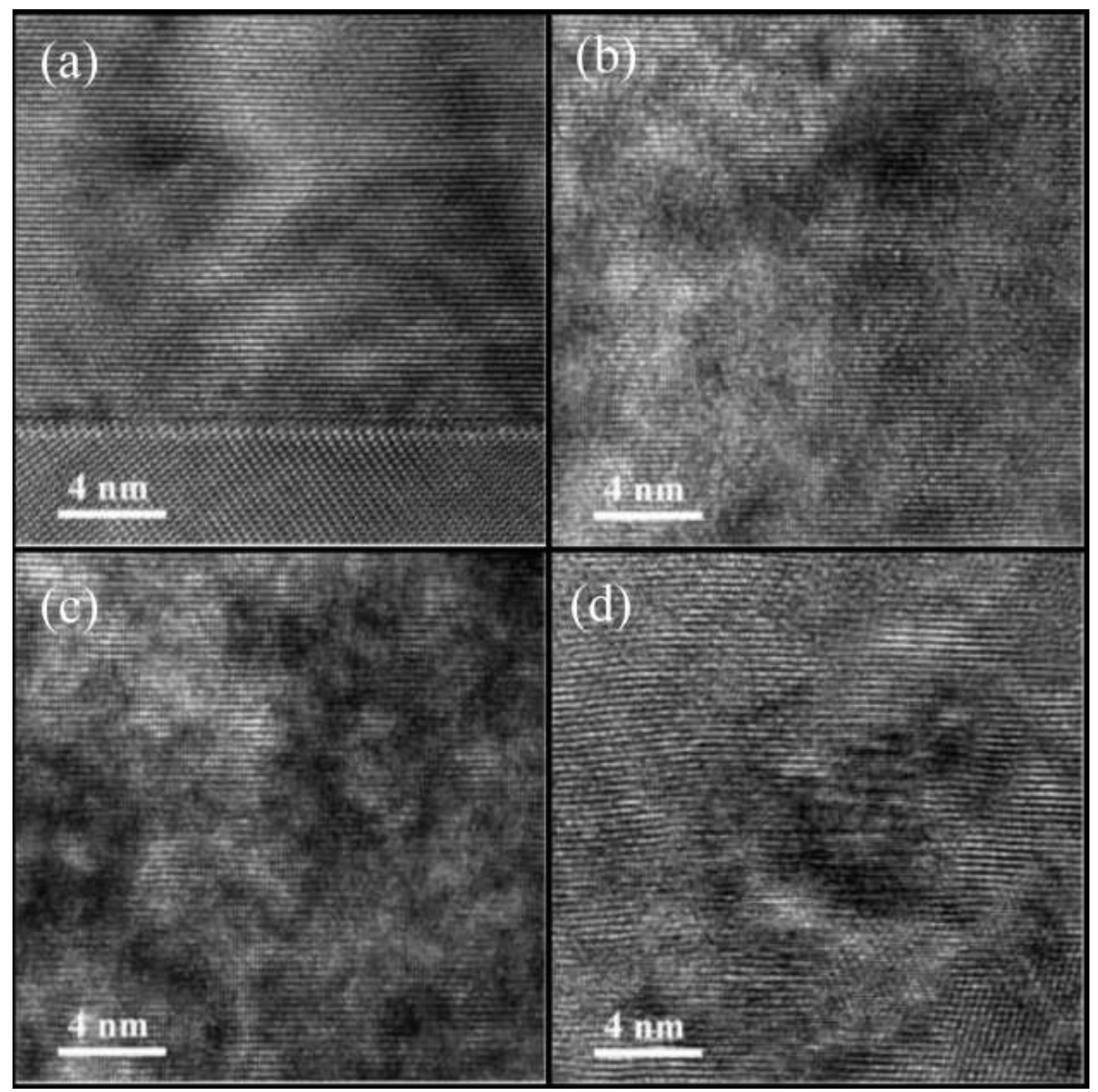

Fig. 6. Lattice resolved images of sample ML-AlN. (a) HT-AlN/sapphire interface, (b) $\mathrm{Al}_{0.83} \operatorname{In}_{0.17} \mathrm{~N}$, (c) $\mathrm{Al}_{0.44} \mathrm{In}_{0.56} \mathrm{~N}$, and (d) InN layers.

To get more insight into the origin of the obtained isotropic strain component in the films, HRTEM, STEM, and SAED were used to investigate the microstucture of the $\mathrm{Al}_{1-\mathrm{x}} \operatorname{In}_{\mathrm{x}} \mathrm{N}$ multilayer samples ML-AlN and ML-ZnO, as is shown in Figs. 5 and 6. Bright-field TEM images, mass-thickness dependent dark-field STEM images, and SAED patterns are shown in Figs. 5(a)-(b) and Figs. 5(c)-(d) for samples ML-AlN and ML-ZnO, respectively. In the 
bright-field images, the $\mathrm{Al}_{1-\mathrm{x}} \mathrm{In}_{\mathrm{X}} \mathrm{N}$ layers show prominent speckled contrast features, but the sapphire substrate shows even contrast, as shown in Fig. 5(a). This speckled contrast, which is due to the local strain field, shown in TEM images have been attributed to the formation of (clustered) point defects or small structural defects [42-44]. The dark to bright contrast transition from the bottom to the top layers, which is seen in the STEM image, corresponds to the transition from light AlN-rich to heavy InN-rich compounds. The STEM images further show rough interfaces between the $\mathrm{Al}_{1-\mathrm{x}} \mathrm{In}_{\mathrm{x}} \mathrm{N}$ layers and dense column-like domains. These columnar structures which are defined by domain boundaries throughout the layers become more emphasized as the indium content increase (though still epitaxial) and eventually develop as individual nanocolumns in the final InN layer. The insets of Figs. 5(a) and 5(c) show SAED patterns taken from the entire films including all layers as well as the part of sapphire substrate and $\mathrm{ZnO}$, respectively. The $\mathrm{Al}_{1-\mathrm{x}} \mathrm{In}_{\mathrm{x}} \mathrm{N}$ reciprocal lattice points (RLPs) exhibit the same crystalline structure and orientation. The epitaxial relationships of the film (all $\mathrm{Al}_{1-\mathrm{x}} \mathrm{In}_{\mathrm{x}} \mathrm{N}(0 \leq x \leq 1)$ layers $)$ and substrate are confirmed to be, $\mathrm{Al}_{1-}$ ${ }_{\mathrm{x}} \mathrm{In}_{\mathrm{x}} \mathrm{N}\left[\begin{array}{lll}1 & \overline{1} & 00\end{array}\right]\left\|\mathrm{Al}_{2} \mathrm{O}_{3}\left[\begin{array}{lll}11 & \overline{2} & 0\end{array}\right], \quad \mathrm{Al}_{1-\mathrm{x}} \mathrm{In}_{\mathrm{x}} \mathrm{N}(0001) \quad\right\| \quad \mathrm{Al}_{2} \mathrm{O}_{3}(0001) \quad$ and $\mathrm{Al}_{1-}$ ${ }_{\mathrm{x}} \mathrm{In}_{\mathrm{x}} \mathrm{N}[1 \overline{1} 00]\left\|\mathrm{ZnO}[1 \overline{1} 00], \mathrm{Al}_{1-\mathrm{x}} \mathrm{In}_{\mathrm{x}} \mathrm{N}(0001)\right\| \mathrm{ZnO}(0001)$, for sapphire and $\mathrm{ZnO}$, respectively. The shapes of the 0002 and $10 \overline{1} l$ RLPs go from broadened laterally, i.e., in the $\mathrm{Q}_{\mathrm{x}}$ direction, towards broadening circumferentially around the origin, as the indium content increases, which is consistent with the RSM results shown in Fig. 3. This is indicative of a transition towards material with generally poorer crystal quality with a larger degree of mosaic tilts/twists and with increasing amounts of lattice distortions [36].

Lattice resolved images of the HT-AIN, $\mathrm{Al}_{0.83} \operatorname{In}_{0.17} \mathrm{~N}, \mathrm{Al}_{0.45} \operatorname{In}_{0.55} \mathrm{~N}$, and $\mathrm{InN}$ layers in the ML-AlN sample are shown in Figs. 6(a)-6(d), respectively. Fig. 6(a) shows the interface between the HT-AlN seed layer and sapphire substrate. The HT-AlN exhibits a single-crystal 
structure. Very few distortions from point- or small structural defects are observed in this part of the sample as is evident from the uniform lattice and even contrast. In the first $\mathrm{Al}_{0.83} \mathrm{In}_{0.17} \mathrm{~N}$ layer, shown in Fig. 6(b), a high-quality lattice image is observable, however, the amount of imperfections increase as is seen from the introduction of a more spot-like variation in the contrast, interpreted as local strain fields near point defects or small structural defects. A further inhomogeneous contrast is seen in the third $\mathrm{Al}_{0.45} \operatorname{In}_{0.55} \mathrm{~N}$ layer, shown in Fig. 6(c), where significant lattice distortions can be found locally. In the top InN layer [Fig. 6(d)], significant amounts of structural defects cause severe distortions of the lattice.

Hydrostatic stress observed in III-nitride semiconductors has been attributed to the existence of point defects, such as interstitials, vacancies, anti-site occupation, and substitutions in the film, as reported in previous literature [45-48]. Indium-rich nitride alloys have previously been shown to be very sensitive to inclusion of point and structural defects [49]. The reason for formation of point defects was referred to a large mismatch in the covalent radii of III-elements, indium $(0.144 \mathrm{~nm})$, gallium $(0.126 \mathrm{~nm})$, and aluminum $(0.118$ $\mathrm{nm})$, and nitrogen $(0.075 \mathrm{~nm})$ [47-49]. Among point defects, the interstitials and anti-sites of indium at nitrogen positions can result in hydrostatic stress in the films. It has been shown that the interstitial nitrogen is dominant among those point defects in sputtered InN films $[45,46]$. In addition, the substitutions can contribute to structural defects when the elemental content of ternary alloys is within the miscibility gap. More defects appearing in the film is expected when the content of III-elements is close to equality. However, the structural quality of the $\mathrm{Al}_{1-\mathrm{x}} \mathrm{In}_{\mathrm{x}} \mathrm{N}$ films becomes worse as increasing indium content, and the InN films have even lower crystalline quality than all $\mathrm{Al}_{1-\mathrm{x}} \mathrm{In}_{\mathrm{x}} \mathrm{N}(x<1)$ films. The result indicates that the substitutions have a minor effect in contributing the defects in the $\mathrm{Al}_{1-\mathrm{x}} \mathrm{In}_{\mathrm{x}} \mathrm{N}$ films. Therefore we attribute the obtained isotropic strain component in the present $\mathrm{Al}_{1-\mathrm{x}} \mathrm{In}_{\mathrm{x}} \mathrm{N}$ lattices to be primarily associated with $\mathrm{N}$-interstitials. The cause of such defects is likely the plasma- 
surface interaction where low energy nitrogen species $(<30 \mathrm{eV})$ may cause surface defects quenched into the growing crystal. We suggest that schemes for ion-assisted MSE, employing lower energies and higher fluxes, are explored for suppression of defect formation during growth in order to further improve crystalline quality.

\section{CONCLUSIONS}

We have demonstrated RT heteroepitaxial growth of $\mathrm{Al}_{1-\mathrm{x}} \mathrm{In}_{\mathrm{x}} \mathrm{N}(0 \leq x \leq 1)$ films on isostructural substrates, $\mathrm{AlN}, \mathrm{GaN}$, and $\mathrm{ZnO}$, by $\mathrm{MSE}$. All $\mathrm{Al}_{1-\mathrm{x}} \mathrm{In}_{\mathrm{x}} \mathrm{N}$, including single layers and multilayers, exhibit single phase, single crystal wurtzite structure, and follow the orientation of the isostructural templates (substrates) well. The films with $x \leq 0.17$ have the highest crystalline quality. However, $\mathrm{Al}_{1-\mathrm{x}} \mathrm{In}_{\mathrm{x}} \mathrm{N}$ films directly deposited on $c$-plane sapphire shows polycrystalline structure. We therefore conclude that isostructural substrate structure and small lattice mismatch are of critical conditions in determining the $\mathrm{Al}_{1-\mathrm{x}} \mathrm{In}_{\mathrm{x}} \mathrm{N}$ RT heteroepitaxy. Furthermore, multilayers with stepwise graded compositions, giving small lattice mismatch between subsequent layers, can be used for growing high-quality epifilms. Except for thin HT-AlN layers, the strain state presented in all $\mathrm{Al}_{1-\mathrm{x}} \mathrm{In}_{\mathrm{x}} \mathrm{N}$ layers is dominated by isotropic strain component rather than the Poisson deformation. The higher the indium content is in the $\mathrm{Al}_{1-\mathrm{x}} \mathrm{In}_{\mathrm{x}} \mathrm{N}$ films, the more defects are generated. The formation of point and structural defects are attributed to the introduction of $\mathrm{InN}$. Using the strained $\mathrm{InN}$ of material grown under the same conditions as the ternaries, Vegard's law is still applicable to estimate composition for all $x$. The demonstrated RT heteroepitaxy of $\mathrm{Al}_{1-\mathrm{x}} \mathrm{In}_{\mathrm{x}} \mathrm{N}$ by $\mathrm{MSE}$ is encouraging for its future application as an alternative material for high-performance electronics on sensitive substrates. 


\section{ACKNOWLEDGMENTS}

The Swedish Strategic Foundation is gratefully acknowledged for the financial support

through the Nano-N and $\mathrm{MS}^{2} \mathrm{E}$ projects. We thank the Tandem Laboratory at Uppsala University for giving us access to their RBS facility. 


\section{REFERENCES}

[1] V.Y. Davydov, A.A. Klochikhin, R.P. Seisyan, V.V. Emtsev, S.V. Ivanov, F. Bechstedt, J. Furthmüller, H. Harima, A.V. Murdryi, J. Aderhold, O. Semchinova, J. Graul, Phys. Status Solidi B 229 (2002) R1.

[2] J. Wu, W. Walukiewicz, K.M. Yu, J.W. Arger III, E.E. Haller, H. Lu, W.J. Schaff, Y. Saito, Y. Nanishi, Appl. Phys. Lett. 80 (2002) 3967.

[3] C.L. Hsiao, H.C. Hsu, L.C. Chen, C.T. Wu, C.W. Chen, M. Chen, L.W. Tu, K.H. Chen, Appl. Phys. Lett. 91 (2007) 181912.

[4] Y. Nanishi, Y. Saito, T. Yamaguchi, Jpn. J. Appl. Phys. 42 (2003) 2549.

[5] C.L. Hsiao, T.W. Liu, C.T. Wu, H.C. Hsu, G.M. Hsu, L.C. Chen, W.Y. Shiao, C.C. Yang, A. Gällström, P.O. Holtz, C.C. Chen, K.H. Chen, Appl. Phys. Lett. 92 (2008) 042101.

[6] C.L. Hsiao, J.T. Chen, H.C. Hsu, Y.C. Liao, P.H. Tseng, Y.T. Chen, Z.C. Feng, L.W. Tu, M.M.C. Chou, L.C. Chen, K.H. Chen, J. Appl. Phys. 107 (2010) 073502.

[7] F.A. Ponce, D. P. Bour, Nature 386 (1997) 351.

[8] S.Tungasmita, P.O.Å. Persson, L. Hultman, J. Birch, J. Appl. Phys. 91 (2002) 3551.

[9] Y.Taniyasu, M. Kasu, T. Makimoto, Nature 441 (2006) 325.

[10] R. Butté, J.-F. Carlin, E. Feltin, M. Gonschorek, S. Nicolay, G. Christmann, D. Simeonov, A. Castiglia, J. Dorsaz, H.J. Buehlmann, S. Christopoulos, G. Baldassarri, H. von Högersthal, A.J.D. Grundy, M. Mosca, C. Pinquier, M.A. Py, F. Demangeot, J. Phys. D: Appl. Phys. 40 (2007) 6328.

[11] S. Senda, H. Jiang, T. Egawa, Appl. Phys. Lett. 92 (2008) 203507.

[12] M. Gonschorek, J.-F. Carlin, E. Feltin, M.A. Py, N. Grandjean, Appl. Phys. Lett. 89 (2006) 062106.

[13] Z.T. Chen, S.X. Tan, Y. Sakai, T. Egawa, Appl. Phys. Lett. 94 (2009) 213504.

[14] J. Kuzmík, IEEE Electron Devices Lett. 22 (2001) 510. 
[15] T. Seppänen, P.O.Å. Persson, L. Hultman, J. Birch, G. Z. Radnóczi, J. Appl. Phys. 97 (2005) 083503.

[16] T. Seppänen, L. Hultman, J. Birch, M. Beckers, U. Kreissig, J. Appl. Phys. 101 (2007) 043519.

[17] M. Ferhat, F. Bechstedt, Phy. Rev. B 65 (2002) 075213.

[18] T. Matsuoka, Appl. Phys. Lett. 71 (1997) 171902.

[19] K. Barghout, J. Chaudhuri, J. Mater. Science 39 (2004) 5817.

[20] K. Kubota, Y. Kobayashi, K. Fujimoto, J. Appl. Phys. 66 (1989) 2984.

[21] R. R. Reeber, K. Wang, Mat. Res. Soc. Symp. 622 (2000) T6.35.1.

[22] J. Birch, T. Joelsson, F. Eriksson, N. Ghafoor, L. Hultman, Thin Solid Films 514 (2006) 10.

[23] M. Kim, J. Ohta, A. Kobayashi, H. Fujioka, Appl. Phys. Lett. 91 (2007) 151903.

[24] K. Ueno, A. Kobayashi, J. Ohta, H. Fujioka, H. Amanai, S. Nagao, H. Horie, Phys. Status Solidi: Rapid Res. Lett. 3 (2009) 58.

[25] K. Sato, J. Ohta, S. Inoue, A. Kobayashi, H. Fujioka, Appl. Phys. Exp. 2 (2009) 011003. [26] T.S. Yeh, J.M. Wu, W.H. Lan, Thin Solid Films 517 (2009) 3204.

[27] M. Junaid, C.L. Hsiao, J. Palisaitis, J. Jensen, P.O.Å. Persson, L. Hultman, J. Birch, Appl. Phys. Lett. 98 (2011) 141915.

[28] K. Lorenz, N. Franco, E. Alves, I. M. Watson, R.W. Martin, K. P. O’Donnell, Phy. Rev. Lett 97 (2006) 085501.

[29] http://www.simnra.com

[30] T. Suzuki, S. Hishita, K. Oyoshi, R. Souda, Surf. Sci. 437 (1999) 289.

[31] E.A. Soares, M.A. Van Hove, C.F. Walters, K.F. McCarty, Phy. Rev. B 65 (2002) 195405.

[32] M. Ying, X. Du, Z. Mei, Z. Zeng, H. Zheng, Y. Wang, J. Jia, Z. Zhang, Q. Xue, J. Phys. 
D: Appl. Phys. 373058 (2004).

[33] C.L. Hsiao, L.W. Tu, M. Chen, Z.W. Jiang, N.W. Fan, Y.J. Tu, K.R. Wang, Jpn. J. Appl. Phys. 44 (2005) L1076.

[34] V. Darakchieva, J. Birch, M. Schubert, T. Paskova, S. Tungasmita, G. Wagner, A. Kasic, B. Monemar, Phy. Rev. B 70 (2004) 045411.

[35] Z. Dridi, B. Bouhafs, P. Ruterana, Semicond. Sci. Technol. 18 (2003) 850.

[36] M.A. Moram, M. E. Vickers, Rep. Prog. Phys. 72 (2009) 036502.

[37] A. F. Wright, J. Appl. Phys. 82 (1997) 2833.

[38] J.M. Mánuel, F.M. Morales, J.G. Lozano, D. González, R. García, T. Lim, L. Kirste, R. Aidam, O. Ambacher, Acta Mater, 58 (2010) 4120.

[39] F.M. Morales, D. González, J.G. Lozano, R. García, S. Hauguth-Frank, V. Lebedev, V. Cimalla, O. Ambacher, Acta Mater. 57 (2009) 5681.

[40] M. Junaid, D. Lundin, J. Palisaitis, C.L. Hsiao, V. Darakchieva, J. Jensen, P.O.Å. Persson, P. Sandström, W.J. Lai, L.C. Chen, K.H. Chen, U. Helmersson, L. Hultman, J. Birch, J. Appl. Phys. 110 (2011) 123519.

[41] C. Kisielowski, J. Krüger, S. Ruvimov, T. Suski, J.W. Ager III, E. Jones, Z. LilientalWeber, M. Rubin, E.R. Weber, M.D. Bremser, R.F. Davis, Phys. Rev. B 54 (1996) 17745.

[42] J. Yamasaki, Y. Ohno, S. Takeda, Y. Kimura, Phil. Mag. 83 (2003) 151.

[43] M.L. Jenkins, J. Nucl. Mater. 216 (1994) 124.

[44] I. Petrov, P.B. Barna, L. Hultman, J.E. Greene, J. Vac. Sci. Technol. A. 21 (2003) S117.

[45] K.S.A. Butcher, A.J. Fernandes, P.P.-T. Chen, M. Wintrebert-Fouquet, H. Timmers, S.K. Shrestha, H. Hirshy, R.M. Perks, B.F. Usher, J. Appl. Phys. 101 (2007) 123702.

[46] D.H. Kuo, C.H. Shih, Appl. Phys. Lett. 93 (2008) 164105.

[47] J. Neugebauer, C.G. Van de Walle, Phy. Rev. B 50 (1994) R8067. 
[48] T. Obata, J.I. Iwata, K. Shiraishi, A. Oshiyama, J. Crystal Growth 311 (2009) 2772.

[49] C. Kisielowski, T.P. Bartel, P. Specht, F.-R. Chen, T.V. Shubina, Physica B 401/402 (2007) 639. 